\title{
O processo eleitoral para escolha de gestor (a) escolar em Abaetetuba/PA
}

\author{
Benedito Antonio Nonato Pinheiro ${ }^{1}$
}

Resumo: O presente estudo evidencia o Processo Eleitoral para escolha de Gestor (a) Escolar no contexto educacional da Rede Pública Municipal de Ensino de Abaetetuba/ PA. Abordando, para tanto, aportes teóricos e legais, como: ARAÚJO (2011), BRASIL (2004), DOURADO (2006), GADOTTI (2014), FERRANTI (2013), PARO (2015), Lei Municipal 182/2004. Assim como, elucida Dados Estatísticos, o IDEB - Índice de Desenvolvimento da Educação, o Quadro Demonstrativo de Processos Eleitorais do contexto educacional em foco e a necessidade de toda a comunidade escolar participar ativamente do processo ensino-aprendizagem.

Palavras chave: Gestão Democrática - Processo Eleitoral - Lei Municipal 182/2004.

Abstract: This study evidences the Electoral Process for the Choice of School Manager in the Educational Context of the Abaetetuba/PA Municipal Public Education Network. In order to do so, theoretical and legal contributions, such as: ARAÚJO (2011), BRASIL (2004), DOURADO (2006), GADOTTI (2014), FERRANTI (2013), PARO (2015), Municipal Law 182/2004. As well as, elucidates Statistical Data, the IDEB - Education Development Index, the Demonstration Chart of Electoral Processes of the educational context in focus and the need of the whole school community to participate actively in the teaching-learning process.

Keywords: Democratic Management - Electoral Process - Municipal Law 182/2004.

\footnotetext{
${ }^{1}$ Mestre em Educação; Pedagogo; Téc. de Referência do Novo Mais Educação (2017-2018), Coord. dos Conselhos Escolares (2009-2016) da Secretaria Municipal de Educação de Abaetetuba/PA; Coordenador Pedagógico na Secretaria de Estado de Educação do Pará (2012-2018); e-mail: bn.pinheiro@bol.com.br
} 


\section{Considerações Iniciais}

Vários instrumentos e ações contribuem para a efetivação da Gestão Democrática enquanto normas e atitudes relevantes para que a liderança seja exercida na sua essência objetivando o compartilhamento de decisões e atitudes de corresponsabilidades.

O processo eleitoral para escolha de gestor (a) escolar é um desse instrumentos, através do qual membros de uma comunidade escolar elegem um (a) na perspectiva de que o (a) mesmo (a) irá mediar as ações educacionais, motivando-os na caminhada coletiva em busca de avanços necessários ao processo ensino-aprendizagem.

Portanto, este estudo evidencia a relevância do Processo Eleitoral para Escolha de Gestor (a) Escolar no percurso da efetivação da Gestão Democrática Educacional. Mas, para acontecer de maneira exitosa, necessita que o referido processo traga em si inúmeros aspectos.

Utiliza-se, para tanto, como pano de fundo o contexto educacional da Rede Pública Municipal de Ensino de Abaetetuba/PA, o qual já conta com Legislação própria que regulamenta tal processo.

\section{Gestão Democrática e o Processo Eleitoral Para Escolha de Gestor (a) Escolar}

Tendo a escola pública a função social de formar o cidadão, isto é, construir conhecimentos, atitudes e valores que tornem o sujeito solidário, crítico, ético e participativo, a mesma deve tornar-se um espaço do exercício de uma autêntica democracia almejando desta forma, a vivencia da autonomia.

Autonomia esta, de acordo com (Brasil, 2018), garantida pela Constituição da República Federativa do Brasil de 1988 com a instituição da democracia participativa e a criação de instrumentos que possibilitem ao povo exercer o poder (Art. $1^{\circ}$ ) e o estabelecimento da gestão do ensino público (Art. 206, Inciso VI). Reafirmada, conforme (Brasil, 1996), pela Lei $n^{\circ} 9.394$ de 20 de dezembro de 1996 - LCB, a qual estabelece as Diretrizes e Bases da Educação Nacional, quando no Art. 14, Inciso II define como princípio da gestão democrática a participação das comunidades escolar e local, em Conselhos de Escola ou equivalentes, evidenciando assim o fundamento constitucional da autonomia da escola, concretizado na criação de novas relações sociais, pautadas na parceria e na participação. 
Com a Gestão Democrática todos os atores envolvidos na educação passam a ter uma visão de grupo, onde juntos, unidos pelos mesmos objetivos, alcançarão melhores resultados, possibilitando desta forma, ao aluno, uma educação de qualidade, que prime pela conquista da cidadania. Neste sentido, compreende-se que,

A gestão democrática é um princípio constitucional que tem como pressuposto o respeito mútuo, a responsabilidade dos atores envolvidos e a efetiva participação nas decisões. Nesse contexto, é fundamental que o plano de educação seja elaborado ou adequado com a participação de todos os atores envolvidos com as questões educacionais. Quanto mais representativa for a participação na elaboração do plano, mais favorecida será a corresponsabilidade nos processos de implantação, execução, acompanhamento e avaliação (Brasil, 2014, p.14).

Democratizar a gestão é partilhar decisões com a comunidade escolar, certos de que no cotidiano irão surgir as respostas adequadas para lidar com pessoas diferentes e ideias divergentes, posto que, na busca de soluções, combinam-se as contribuições e fortalecese a integração do grupo. Atuar em conjunto é o caminho para enfrentar problemas e encaminhar soluções na Escola.

Para que a tomada de decisão seja partilhada, faz-se necessária a implementação de vários mecanismos de participação, tais como; o aprimoramento dos processos de provimento ao cargo de diretor, a criação e consolidação de órgãos colegiados na escola (Conselho Escolar, Conselho de Classe, Associação de Pais e Mestres), o fortalecimento da participação estudantil (Grêmio Estudantil), a construção coletiva do projeto políticopedagógico da escola, a progressiva autonomia da escola, entre outros.

De um tempo para cá, sente-se a necessidade de uma gestão e um contexto escolar, que não somente vislumbrem, mas de fato, empenhem-se em fazer acontecer uma educação a qual,

[...] como apropriação da cultura é direito universal e se apresenta como necessidade intrínseca ao desenvolvimento da sociedade e ao fortalecimento da democracia. Como direito público, sua realização na escola básica, lugar por excelência de seu provimento pelo Estado, deve pautar-se em princípios públicos, ou seja, universalizantes e democráticos [...] (PARO, 2015, p. 63).

Desta forma, a escola pública por excelência não pode eximir-se da tarefa de difundir a democracia, no sentido de estimular a participação e o envolvimento dos agentes envolvidos no processo ensino-aprendizagem, na perspectiva de que assim o façam posteriormente na vida em sociedade.

Para tanto, não basta somente estimular e difundir a democracia e seus princípios, faz-se necessário de fato oportunizar a realização de momentos no contexto escolar por 
meio de ações não esporádicas, vez ou outra, nem tampouco, que seja mero discurso, mas que de fato se conviva numa atmosfera democrática.

A gestão democrática deve estar impregnada por uma certa atmosfera que se respira na escola, na circulação das informações, na divisão do trabalho, no estabelecimento do calendário escolar, na distribuição das aulas, no processo de elaboração ou de criação de novos cursos ou de novas disciplinas, na formação de grupos de trabalhos, na capacitação dos recursos humanos etc. A gestão democrática é, portanto, atitude e método. A atitude democrática é necessária, mas não é suficiente. Precisamos de métodos democráticos de efetivo exercício da democracia. Ela também é um aprendizado, demanda tempo, atenção e trabalho (GADOTTI, 2014, p. 04)

Os autores, portanto, chamam atenção para a necessidade da compreensão de que pode demandar tempo, de que pode dar trabalho, mas que é extremamente relevante evidenciar com atitudes, momentos e métodos, que de fato pretende-se impregnar a atmosfera escolar com o efetivo exercício da democracia, em especial tendo por ponto de partida a Gestão Democrática.

Cabendo aqui, assim, elucidar acerca da conceituação da Gestão Democrática, temática considerada recente no contexto educacional e escolar, mas que traz em si inúmeros aspectos que precisam e devem ser cada vez mais elucidados, para que a mesma não fique apenas no papel, nas leis ou discursos, mas se concretize e possa contribuir para o desenvolvimento da educação e de seus atores.

O autor (DOURADO, 2006) argumenta que "na escola todos têm contribuições e saberes para compartilhar e que todos os processos realizados nos espaços da escola são vivências formativas e cidadãs" (p. 62). Logo, é considerável a necessidade de abrir espaço para que no contexto escolar os agentes envolvidos sejam realmente envolvidos nas discussões, execuções e avaliações das ações, numa perspectiva de coletividade.

Quando há a compreensão de que vários pensando juntos e fazendo acontecer, tende-se a alcançar melhores resultados. Resultados estes que provavelmente contribuirão para o desenvolvimento de um quantitativo representativo de pessoas e não de meros alguns poucos. Mas, obviamente, há de se criar meios para que muitos de fato venham a aderir o processo ensino-aprendizagem, a educação como mola propulsora para o avanço individual e social.

Um desses meios que podem estimular uma dinâmica coletiva e participativa no cotidiano escolar é o Processo Eleitoral para Escolha do (a) Gestor (a) Escolar, haja vista que tende a movimentar a grande maioria dos membros da comunidade escolar, a qual 
espera-se que busque aproveitar de maneira devida essa oportunidade em participar e deliberar sobre algo de extrema relevância.

Neste sentido, com o Processo de Eleição para Gestores, a própria Comunidade Escolar analisará criteriosamente, para posteriormente depositar confiança em alguém que deverá realizar satisfatoriamente a grande articulação da escola, com o envolvimento de todos, ao delegar tarefas, distribuindo trabalho e responsabilidades, entre outros.

O gestor necessita atuar sendo fiel aos objetivos da educação que visa a formação de sujeitos cidadãos. Deve estar respaldado pela comunidade escolar, contar com a ajuda de todos os atores envolvidos, e melhor ainda quando assume o cargo por meio de eleição direta.

Todavia, não se deve atribuir à eleição, por si só, a garantia da democratização da gestão, mas referendar como um instrumento importantíssimo. Neste sentido,

Não queremos, todavia, atribuir à eleição, por si só, a garantia da democratização da gestão, mas referendar essa modalidade como um importante instrumento, a ser associado a outros, para o exercício democrático. Isso implica que, aliado à eleição, é fundamental enfatizar conjuntamente a forma de escolha e o exercício da função. Assim, a forma de provimento no cargo pode não definir o tipo de gestão, mas, certamente, interferir no curso desta. Nesse contexto, a eleição deve ser vislumbrada como um instrumento a ser associado a outros na democratização possível das relações escolares. (Brasil, 2004, p. 40)

Não basta somente promover o Processo Eleitoral por Escolha do Gestor Escolar, torna-se relevante a existência de outros aspectos para que de fato a gestão esteja pautada na coletividade, na democratização das decisões e uma delas é em especial a atuação do Gestor enquanto líder, enquanto aquele ou aquela que fomenta com palavras e ações para que todos os demais agentes do processo sintam-se e comportem-se também como responsáveis pelo processo.

O sujeito não somente participa do poder; mas usufrui da autonomia de forma consciente, responsável e comprometida, sendo efetivamente colaborador da construção de uma educação humana e cidadã.

Para tanto, a Gestão Democrática necessita realmente trabalhar vislumbrando a humanização do homem, onde o mesmo torna-se sujeito histórico-político. Além do compromisso do gestor com a efetiva prática de Gestão Democrática, faz-se necessário o Poder Público vislumbrar em seu Paradigma Educacional, a Organização Escolar, no intuito da realização de um processo que contribua para a efetivação da cidadania.

Cidadania esta que também perpassa pela participação, por exemplo, dos membros da comunidade escolar no processo de escolha do (a) gestor (a) escolar. Neste sentido, 
busca-se neste estudo evidenciar alguns aspectos do processo eleitoral para escolha de gestor (a) escolar na rede pública municipal de ensino de Abaetetuba/PA. Antes, porém, torna-se válido evidenciar sobre o município de Abaetetuba e o contexto educacional de sua rede pública municipal de ensino.

\section{Abaetetuba: Uma terra Acolhedora e Encantadora}

Palavra de origem tupi-guarani, Abaetetuba significa "lugar de pessoas fortes e valentes". Distante em linha reta $51 \mathrm{~km}$ da capital Belém, a cidade de Abaetetuba está localizada à margem direita do Rio Maratauíra, um dos afluentes do Rio Tocantins. O Rio Maratauíra em frente à cidade recebe as águas do Rio Abaeté e vai desaguar na Baía de Marapatá.

Localizado na mesorregião do nordeste paraense, o município limita-se ao norte com Barcarena e o Rio Pará; ao sul com Igarapé-Miri; a leste com Moju e a oeste com Limoeiro do Ajuru e a Baia de Marapatá.

Possui ligação com a capital por via terrestre através de rodovias estaduais e federais e também por via fluvial tendo o tempo de duração de cada viagem de cerca de duas horas com saídas diárias e frequentes.

Apresenta em 2015 área de unidade territorial de 1.610,408 $\left(\mathrm{km}^{2}\right)$ e uma população estimada em 150.431 habitantes, sendo assim o $7^{\circ}$ município mais populoso do Estado do Pará.

Abaetetuba representa uma encantadora surpresa para quem a visita pela primeira vez. Seu povo é alegre, bastante hospitaleiro e sobretudo, apaixonado por sua terra. Esta afirmação é relatada por grande maioria dos visitantes, sendo que entre os quais alguns resolvem fixar residência na cidade.

Tem uma extensa rede hidrográfica, com rios navegáveis em quase toda a sua extensão, além de incontáveis furos e igarapés. O principal é o Rio Tocantins, que em terras do município, pela margem direita, recebe as águas do Rio Meruú, também conhecido como Maratauíra.

Na geografia, de acordo com Abaetetuba (2017), “o município possui uma rede hidrográfica bastante vasta, navegável em quase toda a sua extensão. Existem cerca de 72 ilhas que constituem a chamada Região das Ilhas". É na região das ilhas onde estão estabelecidos os ribeirinhos, às margens dos inúmeros rios, igarapés e furos.

Moradores estes que também já vivenciam aspectos típicos do desenvolvimento urbano como: energia elétrica, casas em alvenaria, televisor com parabólica e/ou canais pagos, assim como mazelas sociais como a criminalidade e as drogas. 
É comum observamos famílias inteiras em suas "rabetas, lanchas, rabudos» (embarcações motorizadas), trafegando através dos inúmeros igarapés, furos e rios, que existem entre as inúmeras ilhas, com destino à cidade ou outra localidade nas mais diversas ocupações ou atividades. Se observarmos o porto de Abaeté pela manhã, constaremos isso.

Sua história apresenta ligações aos jesuítas que tinham a missão de evangelizar os povos, em especial aqueles ainda não haviam passado pelo processo civilizatório.

O Município de Abaetetuba está relacionado com a história da Vila de Beja, que constituem Vilas distintas; posteriormente, foram incorporadas e passaram a pertencer geograficamente ao mesmo município. Os frades capuchos de Santo Antônio, após fundarem o Convento do Una, em Belém, em 1617, passaram a percorrer as terras onde habitavam os índios remanescentes da tribo Mortiguar, e nesse território construíram uma aldeia com caráter de missão religiosa. O Governador Francisco Xavier de Mendonça Furtado denominou a nova aldeia de Samaúma. Tempos depois, a aldeia de Samaúma foi instalada como Freguesia, com o nome de São Miguel de Beja. A Vila de Abaeté, assim como Beja, foi fundada por religiosos que lá residiam (Abaetetuba, 2015a, p. 16).

Assim como os jesuítas, que povoaram a Vila de Beja, hoje distrito e relevante ponto turístico, pois possui a Praia de Beja, bastante procurada, especialmente no mês de julho (férias escolares) pelos munícipes e turistas vindos de vários municípios do Estado (Pará), os portugueses também têm papel importante nesse processo civilizatório de Abaetetuba, porém vieram com o intuito de descobrir para tomar proveito das terras e possíveis riquezas, algo bastante comum no processo de colonização dos povos que compõem a nação brasileira.

O português, Francisco de Azevedo Monteiro, ganhou do Governo uma Sesmaria, a sua escolha, na região do Baixo-Tocantins. Em 1745, Francisco Monteiro e sua família seguiram numa embarcação à procura de um lugar que lhe agradasse e servisse para o estabelecimento de sua Sesmaria. Antes de chegar a Beja, um temporal interrompeu, desviando-o da rota, conseguindo chegar a uma ponta de terra chamada de Jarumã, localizada às margens do rio Maratauira, onde aportou e resolveu se radicar, após ter enfrentado uma forte tempestade. Devido o perigo da tempestade e por ter feito uma promessa a nossa Senhora da Conceição, o mesmo ergueu uma capelinha de palha com a ajuda dos poucos moradores da redondeza, e ali colocou a imagem da virgem de Conceição. Com o passar dos anos, não encontrou terras ricas em cravo - uma das "drogas do sertão"- desiludido, Francisco de Azevedo Monteiro desistiu da Sesmaria e retornou a Belém com sua família (Abaetetuba, 2015b, p. 16).

Então, este território vai gradativamente sendo povoado e desta forma passa também a querer ter legalmente direito de ser considerado como povo autônomo e pleno de seus direitos, conforme bem destacam os relatos históricos, 
Estando anexada ao território de Belém, a freguesia de Abaeté passou a receber, em vários aspectos, grande influência da Capital. Assim, houve um rápido desenvolvimento e cogitou-se da possibilidade de uma Vila de Abaeté. Em 1880, José Araújo Danim, Governador Provincial, desmembrou o território de Abaeté, incluindo Beja, do da capital e o transformou em município autônomo, elevando a antiga freguesia à categoria de Vila. [...] a 23 de março de 1883 [...] foi juridicamente instalada em Abaeté a sede do município de mesmo nome.

A 15 de agosto de 1895 o Dr. João Hozanah de Oliveira, procurador geral do Estado, procedeu à instalação da Cidade. [ ...]

Um ano depois, em 1881, o presidente interino da Câmara em Belém, José Cardoso da Cunha Coimbra instalou no município a Câmara Municipal de Abaeté. A 15 de agosto de 1895 o Dr. João Hozanah de Oliveira, procurador geral do Estado, procedeu à instalação da Cidade. [ ...] (Machado, 2016a, p. 13-15).

Neste sentido, observa-se que este povo gradativamente vem conseguindo evoluir enquanto território e legitimação. Por meio do Decreto Lei $n^{\circ} 4.505$, de 30 de dezembro de 1943, foi instituído o nome Abaetetuba.

Também a partir dos aportes do referido autor, tem-se que até o início da década de 1980, a economia do município se baseava, fundamentalmente, na produção de cachaça nos vários engenhos existentes no município, na fabricação de produtos de cerâmicos em geral (como telhas, tijolos, tachos, alguidás, potes etc).

A economia também era baseada na fabricação de embarcações dos mais variados tipos e portes, de forma artesanal, nos diversos estaleiros existentes no município, no comércio de regatão, na agricultura (no cultivo da cana-de-açúcar, por exemplo, para ser utilizado nos engenhos para produção da cachaça), e no extrativismo vegetal (como do açaí e do palmito, fruto e caule, respectivamente do açaizeiro, de madeiras) e de minerais não metálicos (principalmente o barro utilizado na fabricação de produtos cerâmicos nas olarias).

Ocupavam-se ainda da caça e da pesca, bastante farta nesse período. Uma parte do que era produzido no município era destinada para o abastecimento do comércio local, e outra parte era comercializada com outras cidades do Estado, e até de fora do Estado, via regatão (Machado, 2016b, p. 24 e 25).

A atividade econômica predominante no município é o setor terciário (comércio e serviços), que conta com uma ampla rede de estabelecimentos das mais diversas atividades.

Tendo pequena participação na economia abaetetubense a atividade industrial compõe-se sobretudo do ramo alimentício e de beneficiamento de produtos agro-florestais. 
De um modo geral as indústrias da cidade são de médio e pequeno portes, e distribuem-se principalmente nos ramos de bebidas, moveleiro, madeireiro e oleiro-cerâmico. A cidade conta também com metalúrgicas e estaleiros.

No setor agro-florestal o município destaca-se como o segundo maior produtor de açaí do Pará, como $3^{\circ}$ maior produtor de bacuri e cupuaçu, e como o maior produtor de manga do estado. Outras culturas também marcam fortemente a cadeia vegetal abaetetubense, como mandioca, coco, miriti e bacaba.

Ao contrário da população ribeirinha, a população da zona rural "centro" normalmente sobrevive, basicamente, da agricultura, da pecuária, e da produção artesanal de farinha de mandioca e outros. Para escoar seus produtos fazem uso dos ônibus, dos paus de arara, de carros, de motos, e o que não é incomum, da bicicleta, através dos diversos ramais, os quais permitem o intercâmbio com a cidade. É comum, pela manhã, vermos carros, motos e ônibus, além de bicicletas, lotados em direção à cidade. São por meio desses veículos que circulam entre o campo e a cidade mercadorias e pessoas no dia a dia do município de Abaetetuba.

Em se tratando de dias atuais, Abaetetuba destaca-se por suas lendas; seus encantos naturais; sua engenharia naval, com grande número de estaleiros e habilidosos carpinteiros; e especialmente com o artesanato de miriti, que tem repercussão nacional com o Círio de Nazaré em Belém e chegando a ser divulgado até mesmo em outros países, a ponto de ser considerada a Capital Mundial do Brinquedo de Miriti.

O miriti é o braço das folhas de miritizeiro, palmeira que prolifera em quantidade no município. Sua utilidade é imensa, tudo se aproveitando; a fruta faz parte de nosso cardápio alimentício, dela se faz o vinho que se bebe com peixe assado, camarão, além de doces sorvetes, tintas usadas pelos artistas plásticos, e o tronco da árvore serve para a construção de estiva (pequena ponte) usada como via de transporte que vai do porto até a casa dos ribeiros [...] (Lobato, 2001a, p. 21).

Árvore esta que, portanto, torna-se de grande serventia para os ribeirinhos, haja vista que, pode ser utilizada de inúmeras maneiras.

Entre essas diferentes maneiras, a que tomou maior destaque foi a produção e comercialização do Brinquedo de Miriti, levando a um reconhecimento nacional e internacional e a Criação do MIRITIFEST, Evento Anual no qual se realiza a exposição e comercialização de vários produtos feitos a partir do Miriti e em especial os Brinquedos, este em nível regional, uma vez que em nível internacional já ocorre a participação dos artesãos abaetetubenses na Feira Artesanal, uma das Atividades do Círio de Nossa Senhora de Nazaré em Belém do Pará. 
Os brinquedos de miriti sempre apresentam uma marcante peculiaridade cultural e regional, resultante da influência dos tempos e do meio, com traços e pontilhados revelados pelos tons das cores primárias, retratam a originalidade do artista, oferecendo meios de subsistência dos artesãos (Lobato, 2001b, p. 14).

Muitas pessoas ainda sobrevivem do trabalho informal, na feira do comércio, nas praças e esquinas da cidade, como vendedores de lanche, carregadores, guardadores de bicicleta, carro, moto, nas portas de lojas supermercados, hospitais etc. Ou, como fazem centenas de homens das mais variadas faixas etárias, trabalham como mototaxistas condutores de motos que cobram um valor para levar passageiros de um lugar para outro.

Na região do campo percebe-se que as pessoas trabalham em atividades voltadas para o trabalho em olaria, cultivo da mandioca, manejo do açaí, peconheiros, produção de farinha, pesca artesanal, extração do miriti, artesanato, roçado e cultivo da cana, lavoura, criação de animais de pequenos portes, rabeteiros além do trabalho doméstico para garantir a sobrevivência dos moradores dessas localidades.

Abaetetuba é um município com uma população trabalhadora que desenvolve inúmeras atividades e serviços formais e informais que fortalecem a economia local e contribuem para o engrandecimento do município como um todo e que quando se une em prol de um mesmo objetivo geralmente tem conseguido grandes resultados, como gradativamente se observa no contexto educacional.

\section{O Contexto Educacional Abaetetubense}

No que se refere a uma dinâmica que favoreça os processos coletivos e participativos de decisão, faz-se necessário ressaltar que, no território abaetetubense, um caminho já se vem percorrendo nesta direção, haja vista que há alguns anos o território municipal conta com Instrumentos e Espaços Participativos, bem como com Recursos repassados pelo Governo Federal e políticas em Regime de Colaboração:

> Conselho Municipal de Educação;

> Fórum Municipal de Educação;

$>$ Conselho Municipal do FUNDEB;

> Conselho Municipal de Alimentação Escolar;

> Comissão Gestora do PCCR - Plano de Cargos Carreira e Remuneração;

> Comitê Municipal do Pacto pela Educação; 
Abaetetuba tem em seu território a Rede Municipal, a Rede Estadual, a Rede Federal (Campus de Abaetetuba da UFPA - Universidade Federal do Pará e do IFPA Instituto Federal do Pará), a Rede Privada, as quais ofertam Ensino em Creches, Educação Infantil, Ensino Fundamental Menor e Maior, Ensino Médio, Ensino Profissionalizante e Ensino Superior.

O Contexto Educacional de Abaetetuba, portanto, historicamente tem vivenciado ações que estimulam e buscam fortalecer a gestão democrática, como por exemplo, no que se refere ao processo eleitoral para escolha de gestor escolar temos a experiência significativa do Colégio São Francisco Xavier da Rede Estadual.

É considerado um feito inédito no Estado a realização das eleições diretas para a escolha de seu diretor, ainda na década de 1980. Neste âmbito, o Colégio São Francisco Xavier foi efetivamente o primeiro em todo o Estado do Pará a exercer de forma legítima este mecanismo de democratização por meio da eleição direta. Feito que deve ser considerado, pois, somente, na administração do governo popular do Estado do Pará (de 2007 a 2009), aproximadamente 27 anos, após a primeira eleição para escolha de diretores, realizada na escola é que a rede estadual de ensino torna legitima e legaliza essa forma de escolha dos diretores.

[...] Seu primeiro diretor eleito pela comunidade educativa foi o professor Athaide Feio Neves, no ano de 1983. A Escola contabiliza hoje uma hoje uma sequência de 14 diretores eleitos e legitimados pela comunidade (Araújo, 2012, p. 41-42).

Evidenciando desta forma a garantia da participação da comunidade escolar no processo de escolha do (a) Gestor (a) Escolar, incentivando outras unidades de ensino a também proporcionarem essa que se torna uma relevante conquista coletiva.

A Escola Dom Ângelo Frosi da Rede Municipal de Ensino, por exemplo, anos depois também realizou processos democráticos para escolha do (a) gestor (a). Ressaltando que essas duas escolas ousaram, pois tanto a Rede Estadual quanto a Rede Municipal de Ensino ainda não contavam com Legislação específica que norteava o Pleito Eleitoral.

Como este estudo tem por foco o processo eleitoral democrático para escolha do (a) gestor (a) escolar na rede pública municipal de ensino de Abaetetuba/PA, cabe então, apresentar algumas informações relevantes da referida Rede de Ensino.

Atualmente, a Rede Pública Municipal de Ensino de Abaetetuba/PA conta com 173 Unidades de Ensino, das quais (42) localizadas na Cidade (131) e no Campo (Estradas/Ramais - 49 e Ilhas-82). Oferecem Atividades Educacionais para Alunos da Creche, Educação Infantil, Ensino Fundamental ( $1^{\circ}$ ao $5^{\circ}$ Ano) e EJA - Educação de Jovens e Adultos ( $1^{\mathrm{a}}$ e $2^{\mathrm{a}}$ Etapa do Ensino Fundamental) para 23.248 Alunos. 
Tabela 01 - Demonstrativo de Alunos - Matrícula Inicial/2018

\begin{tabular}{|c|c|c|c|c|c|c|c|c|c|c|c|c|c|c|c|c|}
\hline & \multicolumn{6}{|c|}{ EDUCAÇÃO INFANTIL } & \multicolumn{6}{|c|}{ ENSINO FUNDAMENTAL } & \multicolumn{3}{|l|}{ EJA } & \multirow[t]{2}{*}{ TOTAL } \\
\hline & 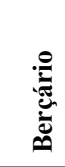 & 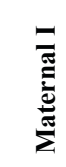 & 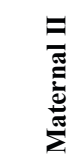 & 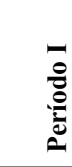 & $\begin{array}{l}= \\
0 \\
0 \\
0 \\
0 \\
0\end{array}$ & 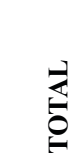 & $\begin{array}{l}0 \\
2 \\
\vdots \\
0\end{array}$ & $\begin{array}{l}0 \\
\sum_{4} \\
\stackrel{1}{N}\end{array}$ & $\begin{array}{l}0 \\
\sum_{4} \\
\text { in }\end{array}$ & \begin{tabular}{l}
0 \\
2 \\
\multirow{2}{*}{} \\
$\dot{0}$
\end{tabular} & $\begin{array}{l}0 \\
\sum_{4} \\
\text { in }\end{array}$ & ְِ & 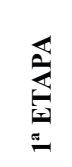 & 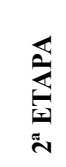 & ְ & \\
\hline Cidade & 170 & 408 & 1087 & 1279 & 1231 & 4175 & 1377 & 1265 & 1635 & 1542 & 1368 & 7187 & 390 & 312 & 702 & 12.064 \\
\hline Ilhas & 0 & 0 & 201 & 681 & 785 & 1667 & 719 & 804 & 1124 & 1038 & 918 & 4603 & 233 & 179 & 412 & 6.682 \\
\hline $\begin{array}{l}\text { Estradas } \\
\text { e ramais }\end{array}$ & 0 & 22 & 359 & 469 & 480 & 1330 & 484 & 473 & 647 & 564 & 564 & 2732 & 245 & 195 & 440 & 4.502 \\
\hline TOTAL & 170 & 430 & 1647 & 2429 & 2496 & 7172 & 2580 & 2542 & 3406 & 3144 & 2850 & 14522 & 868 & 686 & 1554 & 23.248 \\
\hline
\end{tabular}

Fonte: Coordenação de Estatística-Secretaria Municipal de Educação/Abaetetuba, 2018a

Observa-se que a Educação Infantil atende a 7.172 alunos; o Ensino Fundamental por sua vez 14.522 e a Educação de Jovens e Adultos 1.554. Assim como, que mesmo tendo o quantitativo menor de escolas, a cidade possui 12.064, o maior número de alunos da rede, enquanto a área de Ilhas com 82 Escolas apresenta 6.682 alunos.

Rede municipal de ensino esta que felizmente vem apresentando avanço quanto ao Índice de Desenvolvimento Educacional - IDEB, verificando no 4\% $5^{\circ}$ Ano, conforme (Brasil, 2018), evidenciado no site do Instituto Nacional de Estudos e Pesquisas Educacionais Anísio Teixeira - INEP.

Tabela 02 - IDEB - Índice de Desenvolvimento da Educação Básica. Resultados e Metas da Rede Pública Municipal de Ensino de Abaetetuba/PA

\begin{tabular}{|c|c|c|}
\hline ANO & META & IDEB \\
\hline 2005 & & 2.8 \\
\hline 2007 & 2.8 & 3.1 \\
\hline 2009 & 3.2 & 3.6 \\
\hline 2011 & 3.6 & 3.9 \\
\hline 2013 & 3.8 & 4.0 \\
\hline 2015 & 4.1 & 4.4 \\
\hline 2017 & 4.4 & \\
\hline
\end{tabular}

Fonte: INEP/Brasil, 2018

A Tabela, portanto, demonstra que o IDEB alcançado vem sempre superando as metas projetadas para cada ano de verificação, situação contribuída mais ainda no ano de 2015 quando várias unidades de ensino conseguiram alcançar meta projetada para 2017, 2019 e até mesmo para 2021. 
Entre vários aspectos que vêm contribuindo para que esses índices sejam obtidos pode-se dizer que é o processo eleitoral para escolha de gestor (a) escolar, no sentido de que o mesmo incentiva comprometimento coletivo, ou seja, a grande maioria dos atores envolvidos no processo ensino-aprendizagem, percebem que necessitam e devem contribuir participando e acompanhando as ações do cotidiano escolar.

\section{O processo eleitoral para escolha de gestor (a) escolar na rede pública municipal de ensino de Abaetetuba/PA}

A rede pública municipal de ensino de Abaetetuba/PA, conta com o processo de eleição para gestores de escolas da rede municipal, tendo por instrumento normatizador a Lei Municipal 182 de 3 de dezembro de 2004, fomentando assim, uma das ações relevantes para a efetivação da perspectiva de Gestão Democrática no âmbito educacional.

Art. $2^{\circ}$ - Os Diretores das Escolas Públicas Municipais serão eleitos, em votação direta, pela Comunidade Escolar de cada Unidade de Ensino, que tenha a partir de 240 alunos;

Art. $4^{\circ}$ - Estarão aptos a votar todos os que compõem a comunidade escolar, professores, especialista em educação, pessoal de apoio, alunos maiores de doze anos, pais ou responsáveis por cada aluno, membros do Conselho Escolar, todos, devidamente cadastrados pela Comissão Eleitoral no período fixado no Regimento Eleitoral (Abaetetuba, 2004a).

A referida Lei preceitua que o Conselho Escolar da Unidade de Ensino Municipal que possua a partir de 240 alunos matriculados (Educação Infantil, Ensino Fundamental e EJA) e possa realizar o Pleito para Escolha Direta do (a) Gestor (a) Escolar, contando com a participação dos agentes envolvidos no processo ensino-aprendizagem.

Esse quantitativo de alunos tem sido um grande entrave, haja vista que poucas Unidades de Ensino do referido Contexto Educacional apresentam o número mínimo exigido em Lei, especialmente as localizadas na Área do Campo (Estradas/Ramais e Ilhas), inviabilizando o respaldo legal para realização de tão relevante Processo Democrático.

Em se tratando de números torna-se relevante aqui demonstrar alguns números acerca de Processos Eleitorais para Escolha de Gestor (a) Escolar ocorridos no contexto em questão. 
Tabela 03 - Demonstrativo de Processos Eleitorais Realizados na Rede Pública Municipal de Ensino de Abaetetuba/PA (2005 a junho/2018)

\begin{tabular}{|c|c|c|c|}
\hline $\mathbf{N}^{\mathbf{0}}$ & ESCOLA & LOCALIDADE & $\begin{array}{l}\text { QUANTITATIVO DE } \\
\text { PROCESSOS ELEITORAIS }\end{array}$ \\
\hline 01 & Carlaide Cardoso Ferreira Jorge & Cidade & 04 \\
\hline 02 & Comandante Germano & Cidade & 04 \\
\hline 03 & Cônego Luís Varela & Cidade & 03 \\
\hline 04 & Criança Esperança & Cidade & 02 \\
\hline 05 & Dom Ângelo Frosi & Cidade & 03 \\
\hline 06 & Dr. Francisco Leite Lopes & Cidade & 02 \\
\hline 07 & Dr. Vicente Maués & Cidade & 03 \\
\hline 08 & EMEI Algodoal & Cidade & 01 \\
\hline 09 & Francisco Marques Ferreira & Cidade & 04 \\
\hline 10 & Gov. Magalhães Barata & Cidade & 01 \\
\hline 11 & Joaquim Mendes Contente & Cidade & 01 \\
\hline 12 & Laura dos Santos Ribeiro & Cidade & $\mathbf{0 3}$ \\
\hline 13 & Maria Zaíde Cardoso & Cidade & 04 \\
\hline 14 & Mariuadir Santos & Cidade & $\mathbf{0 3}$ \\
\hline 15 & Maximiano Antônio Rodrigues & Cidade & $\mathbf{0 3}$ \\
\hline 16 & Pedro Ferreira Costa & Cidade & 04 \\
\hline 17 & Santa Anastácia & Cidade & $\mathbf{0 3}$ \\
\hline 18 & Santa Clara & \begin{tabular}{|l|} 
Cidade \\
\end{tabular} & 02 \\
\hline 19 & Santa Luzia & Cidade & 02 \\
\hline 20 & São José & Cidade & 01 \\
\hline 21 & Dr. João Miranda & Colônia Velha & 01 \\
\hline 22 & Maria do Carmo & Vila de Beja & 02 \\
\hline 23 & Nossa Senhora da Paz & Rio Arumanduba & 01 \\
\hline 24 & Nossa Senhora do P. Socorro & Rio Quianduba & 01 \\
\hline 25 & São João Batista & Rio Campompema & 01 \\
\hline
\end{tabular}

Fonte: Coordenação de Conselhos Escolares - Secretaria Municipal de Educação/Abaetetuba, 2018b

O Quadro acima evidencia que na rede pública municipal de ensino de Abaetetuba/ PA, de 2005 até junho de 2018, já ocorreram 59 Processos Eleitorais, contemplando 25 unidades de ensino.

Das 25 unidades de ensino que realizaram o processo eleitoral para escolha do (a) gestor (a) escolar, 20 são da cidade e cinco do Campo (três - Ilhas e dois - Estradas/ Ramais), o que reforça a necessidade de atualização da referida lei para alteração do quantitativo de alunos, para que um número bem maior de escolas possa realizar, com respaldo legal, o tão necessário e relevante processo democrático de escolha do (a) gestor (a) escolar.

Em relação a este relevante aspecto que denota sobre gestão democrática na rede pública municipal de Abaetetuba, 
[...] a escolha dos diretores se deu por meio de eleição direta, uma demonstração da autonomia da comunidade educativa que chegava às diversas escolas e localidades. A exemplo temos a primeira diretora empossada, por eleição direta, no dia 07/05/2006, que foi a professora Silene André Barreto, da Escola Nossa Senhora da Paz, localizada no Rio Arumanduba, região ribeirinha (Ferranti, 2013, p. 81).

Fato este que pode-se considerar não uma mera coincidência mas uma justa homenagem aos moradores das Ilhas de Abaetetuba, haja vista que, historicamente, têm sido incansáveis na luta organizada e participativa, visando garantir que suas vozes e opiniões sejam ouvidas e respeitadas, fruto da forte participação nos movimentos promovidos pelas Comunidades Eclesiais de Base - CEBs, aliando aspectos religiosos e sociais.

[...] Como traço substancial da nova internalização favorecida pelas CEBs encontra-se uma nova relação com o sagrado, que implica agora a centralidade da conscientização, um novo compromisso ético e político e ênfase na participação em lutas populares. O sentimento de pertença à comunidade traz consigo uma nova visão de mundo, uma nova simbologia e outras práticas coletivas. [...] (Coutinho, 2009, p. 182).

Desta forma, Comunidade Eclesial de Base deve preocupar-se em aliar religiosidade e consciência social, no sentido de poder participar e opinar sobre as ações que devem beneficiar a população, como por exemplo, a redução do quantitativo exigido em lei para que mais unidades de ensino da rede pública municipal de ensino de Abaetetuba/PA possam realizar o pleito eleitoral para escolha diretora do gestor escolar, haja vista que pouquíssimas na região das Ilhas alcançam o quantitativo de alunos exigido em lei.

Ainda versando acerca do quantitativo mínimo exigido em Lei para a realização do processo democrático de eleição para gestor escolar, até mesmo as escolas da cidade vêm enfrentando problemas, devido a diminuição no número de alunos, algumas não mais enquadram-se no respaldo da legislação municipal, que preceitua sobre essa matéria, deixando assim de realizarem o pleito.

Por outro lado, mesmo tendo o número de alunos compatível com o exigido em lei, há ainda escolas que por inúmeros fatores, infelizmente, não fazem uso do direito e respaldo legal e preferem não realizar o pleito democrático para escolha do gestor escolar, optando assim, em ter um (a) gestor (a) nomeado pelo poder público local.

Há de se implementar estudos e discussões visando a urgente e necessária atualização da legislação em questão para que ocorram mudanças significativas na condução do processo. Preconizado por meio PME - Plano Municipal de Educação 
(2005-2025), na Meta 14 sobre Gestão Democrática e Financiamento da Educação e devidamente reiterado pela IV Conferência Municipal de Educação realizada no ano em curso.

14.11 - Promover através do Fórum Municipal de Educação as discussões mediante participação da sociedade, de forma democrática, sobre alterações legislativas das Leis Municipais: Lei Orgânica, Regimento Unificado das Escolas Municipais, Regime Jurídico único, Lei 182/2004 (Lei para Eleição de Gestores Escolares Municipais) [...];

14.12 - Assegurar o processo eleitoral para escolha de Gestores das Escolas do território abaetetubense, conforme Legislação vigente; (Abaetetuba, 2015c, p. 229-230)

Reduzir o quantitativo de alunos mencionados em lei objetivando respaldar a realização do processo eleitoral para escolha do (a) gestor (a) escolar é relevante sim, bem como o fato de que os profissionais que participarem e vencerem os pleitos necessitam exercer efetivamente a postura de Gestores Democráticos, sendo líderes, motivadores, profissionais que coloquem-se na condição de mediadores, recebendo o devido apoio, tanto da gestão municipal como da comunidade escolar que os (a) elegeu, para que desta forma, consigam conduzir as melhorias necessárias.

Demonstrando desta forma que sentiram-se motivados pela possibilidade de ampliação na Jornada de Trabalho de 100 para 200h, com a devida remuneração, conforme preceitua a referida Lei em seu Art. $3^{\circ}$, Inciso VI - “Tenha disponibilidade para o cumprimento de regime de trabalho de 200 (duzentas horas mensais)", como também pela oportunidade em contribuir significativamente com o sucesso do processo ensinoaprendizagem nos seus mais diversos aspectos.

Assim, estarão deixando suas marcas na história da escola e da comunidade, pois devido ao forte impacto que uma educação de qualidade provoca na vida dos estudantes e dos que os cercam, aqueles que observam o comprometimento passam a admirar e tendem a valorizar o (a) determinado profissional, gerando a possibilidade de estender um pouco mais a atuação na gestão, haja vista que, a Lei Municipal 186/2004 que rege ao Processo Eleitoral para Escolha do (a) Gestor Escolar assegura um mandato de 03 anos e a reeleição.

Art. 16 - Da eleição e posse do (a) novo diretor (a):

I - A eleição para a escolha do Diretor terá mandato por 03 (três) anos, podendo ser reeleito somente uma vez.

II - Se o Diretor eleito não corresponder às funções para o cargo que fora eleito,

o Conselho Escolar poderá analisar o caso e deliberar através de Assembleia 
BENEDITO ANTONIO NONATO PINHEIRO $\stackrel{6}{6}$ o PROCESSO ELEITORAL PARA ESCOLHA DE (...)

Geral com a comunidade escolar o que fazer para solucionar a problemática. (Abaetetuba, 2004b)

Por outro lado estimula a comunidade escolar além de contribuir com o sucesso da gestão escolar a também exercer a fiscalização, até por se tratar de uma instituição pública e que não apenas é mantida com recursos públicos, como também muitas vezes lida com recursos públicos repassados pelo Governo Federal ao Conselho Escolar, órgão este composto por representantes das diferentes categorias de atores do processo ensinoaprendizagem que necessita, caso seja, necessário intervir e evitar a prática de gestores centralizadores de decisões e que queiram tirar proveito da coisa pública.

Em suma, o Processo Eleitoral deve contribuir para que a gestão escolar seja efetivamente democrática, alicerçada em decisões coletivas, fomentando a participação e o envolvimento da comunidade do entorno. Comunidade esta que envolvida tende a sentir-se e atuar enquanto maior beneficiada pelo sucesso obtido quando da oferta de uma educação, de fato, de qualidade, comprometendo-se enquanto corresponsável lutar para que o alunado usufrua de atividades escolares que o auxilie a se desenvolver tanto na formação quanto na conscientização de que pode e deve ser protagonista de sua história e do meio que o cerca.

\section{Considerações Finais}

Em todo grupo para que as situações ocorram obedecendo a uma determinada organização, alguém ou algumas pessoas necessitam assumir o papel de liderança. No contexto educacional ou escolar não é diferente. Faz-se primordial que haja uma liderança, e nos dias atuais, bem mais do que antes, preferencialmente de maneira coletiva, democrática.

Assim, sinaliza uma gestão compartilhada, na qual o que prevalece é a ideia e necessidade da maioria, reforçada pela concepção de Conselho Escolar enquanto colegiado formado por representantes das diferentes categorias da comunidade escolar e local; da elaboração e implementação coletiva do Projeto Político Pedagógico; da Associação de Pais e Mestres; do Grêmio Estudantil e do Processo Eleitoral para Escolha do (a) Gestor (a) Escolar, espaços coletivos de grande relevância para a efetivação da Gestão Democrática no contexto escolar.

O presente estudo evidenciou portanto um desses espaços coletivos, o processo eleitoral para escolha de gestor (a), em especial, no contexto educacional da rede pública 
municipal de ensino de Abaetetuba/PA, com ênfase em aspectos como: o quantitativo de processos já ocorridos; a necessidade em implementar estudos no intuito de atualizar a Legislação Municipal que preceitua o referido processo; a redução no quantitativo do alunado, ampliando o leque de unidades de ensino que poderão, com respaldo legal, realizar o pleito.

Pleito este, que efetivamente, consiga contribuir com a gestão democrática tornando-se um mecanismo de incentivo à coletividade, ao compartilhamento das tarefas e decisões, numa perspectiva de corresponsabilidade, onde mesmo em meio a uma "disputa", haja inicialmente a preocupação em fortalecer e unificar o espaço escolar, para posteriormente ocorra o engajamento com a luta por avanços significativos, que proporcionem, em especial, êxito no processo ensino-aprendizagem.

\section{Referências}

ABAETETUBA (2015). Lei 437/2015 - Plano Municipal de Educação. Abaetetuba/PA: Gabinete da Prefeita Municipal de Abaetetuba em 24 de junho.

(2004). Câmara Municipal de. Lei no 182/2004 de 03 de Dezembro de 2004 -Eleição Direta de Diretor nas Escolas Públicas Municipais. Promulgada em 03 de dezembro de 2004. Abaetetuba/PA.

(2018). Demonstrativo de Alunos - Matrícula Inicial. Abaetetuba/PA: Coordenação de Estatística, Secretaria Municipal de Educação. Prefeitura Municipal.

(2018). Demonstrativo de Processos Eleitorais realizados na Rede Pública Municipal de Ensino de Abaetetuba/PA (2005 a junho/2018). Abaetetuba/PA: Coordenação de Conselhos Escolares, Secretaria Municipal de Educação, Prefeitura Municipal.

- Geografia. http://www.abaetetuba.pa.gov.br/portal/abaetetuba/cidade/ geografia. (Consultado em 21/08/2018).

ARAÚJO, Maria Auxiliadora Maués. A Gestão Premiada: A experiência de gestão do C.E.E.M.R.C. São Francisco Xavier em Abaetetuba - Pará, 2011, 220f. Tese de Doutorado em Educação - Programa de Pós-Graduação em Educação da Universidade Federal do Pará - UFPA, Belém, 2012. repositório.ufpa.br/jspui/bitstream/2011/2739/1/Tese_ GestaoPremiadaExperiencia.pdf (Consultado em 27/07/2018).

BRASIL (2004). Conselhos Escolares: Democratização da escola e construção da cidadania. Elaboração Ignez Pinto Navarro... [et al.] - Brasília: MEC/SEB - Programa de Fortalecimento dos Conselhos Escolares. vol.01. 
BENEDITO ANTONIO NONATO PINHEIRO $\stackrel{6}{\bullet}$ O PROCESSO ELEITORAL PARA ESCOLHA DE (...)

. IDEB (Índice de Desenvolvimento da Educação Básica) - Resultados e Metas. INEP - Instituto Nacional de Estudos e Pesquisas Educacionais Anísio Teixeira. http:// ideb.inep.seam.?cid=142793 (Consultado em 30/07/2018).

- Planejando a próxima década: Alinhando os Planos de Educação. Ministério da Educação/Secretaria de Articulação com os Sistemas de Ensino - MEC/SASE. http:// pne.mec.gov.br/images/pdf/pne_alinhando_planos_educacao.pdf (Consultado em 31/07/2018).

Constituição da República Federativa do Brasil de 1998-CF/88. www.planalto. gov.br/ccivil_03/constituicao/constituicao.htm (Consultado em 29/09/2018).

(1996). Lei no 9.394 de 20 de dezembro de 1996 - LDB. Estabelece as diretrizes e bases da educação nacional. Brasília-DF: Diário Oficial da União, 23 de dezembro.

COUTINHO, Sérgio Ricardo. ComunidadesEclesiais: presente, passadoe futuro. Interações - Cultura e Comunidade, v. 4, n. 6, p. 173-185, 2009. file.//F:/COMUNIDADE\%20 ECLESIAIS\%20DE\%20BASE.pdf (Consultado em 28/07/2018).

DOURADO, Luis Fernandes (2006). Conselho Escolar, Gestão Democrática da Educação e Escolha de Diretor. - Brasília: MEC, SEB, novembro - Programa de Fortalecimento dos Conselhos Escolares. vol. 05.

FERRANTI, Adelino (2013). A Política Educacional no Município de Abaetetuba (PA) no período de 2005-2008: Realidade e limites. 122f. Dissertação (Mestrado). Programa de Pós-Graduação em Educação. Belém: Instituto de Ciências e Educação - Universidade Federal do Pará - UFPA.

GADOTTI, Moacir (2014). Convite à leitura de Paulo Freire. São Paulo: Scipione.

LOBATO, Maria de Nazaré Carvalho (2001). Nossa Arte, Nossa Vida. $1^{\text {a }}$ ed. Abaetetuba/ PA.

MACHADO, Jorge (2016). História de Abaetetuba: com referências na história social e econômica da Amazônia. Abaetetuba/PA: Edição do Autor.

PARO, Vitor Henrique (2015). Diretor Escolar (Livro Eletrônico): Educador ou Gerente? São Paulo: Cortez - Coleção Questões de nossa época; vol.56. pdf.

Recebido em 22/11/2018

Aprovado em 22/12/2008 